\title{
Efficacy of cell block immunocytochemistry in the diagnostic workup of non hodgkin lymphoma-experience from a tertiary care hospital in North India
}

\author{
Pradyumn Singh ${ }^{1}$, Anurag Gupta ${ }^{2, *}$, Namrata P Awasthi ${ }^{3}$, Ashish Singhal ${ }^{4}$, Gaurav Gupta ${ }^{5}$ \\ ${ }^{1,2}$ Professor, ${ }^{3,4}$ Associate Professor, ${ }^{5}$ Assistant Professor, ${ }^{1-3}$ Dept. of Pathology, ${ }^{4}$ Dept. of Surgical Oncology, ${ }^{5}$ Dept. of Medical \\ Oncology, Dr Ram Manohar Lohia Institute of Medical Sciences, Lucknow Uttar Pradesh
}

*Corresponding Author:

Email: ganuragdr@gmail.com

Received: $25^{\text {th }}$ November, 2017

Accepted: $1^{\text {st }}$ January, 2018

\begin{abstract}
The WHO 2016 update on lymphoid neoplasms incorporates criteria independent of tissue architecture in the diagnosis and subclassification of non-Hodgkin lymphoma. Thus, lymphoid neoplasms with characteristic immunophenotypes and/or cytomorphology could be classified with FNA material with appropriate use of ancillary methods. We analysed the efficacy of cytomorphology and cell block immunocytochemistry (CB-ICC) in in diagnostic workup of non-Hodgkin lymphoma diagnosis on FNA material. 65 clinically suspected cases of lymphoma presenting with lymphnode enlargements were analysed. FNAC and CB-ICC were performed and compared with the subsequent biopsy. The sensitivity, specificity, PPV and NPV of CBICC in the diagnosis of NHL were $84.6 \%, 75 \%, 95.6 \%$, and $42.8 \%$, respectively in our study.

We also observed that use of CB-ICC can have significant logistic implications in patient management in terms of reducing the turn-around time to diagnosis and improving the accuracy in diagnosis on FNAC. ICC on cell blocks can easily be done on FNA material and is a very useful adjunct to FNAC in establishing the diagnosis in a suspected case of NHL especially when a biopsy is not available.
\end{abstract}

Keywords: Cell block immunocytochemistry, NHL, FNAC, Ancillary methods.

\section{Introduction}

Non-Hodgkin lymphomas (NHL) are a heterogeneous group of malignancies of the lymphoid system. These include a diverse group of tumors of Bcell, T-cell, and NK-cell origin. The 'gold standard' for diagnosis of non-Hodgkin lymphoma is histopathological examination of exicisional biopsy with Immunohistochemistry. ${ }^{1}$ However surgical biopsy may not always be the best clinical approach such as when there are no easily accessible lymph nodes and a biopsy requires a major invasive procedure or in high tumor burden cases, where crucial time to start therapy may be lifesaving, or in cases where patient is not fit to undergo a surgical procedure.

Fine needle sampling of involved node or extranodal tumor is a well-established modality but conventional cytomorphology assessment may not be enough for diagnosis. ${ }^{2}$ Fine needle aspiration (FNA) cytology is widely used in the investigation of lymphadenopathy, and offers very quick preliminary diagnosis with minimal trauma to the patient at considerably lower cost than surgical biopsy. Thus, it is very helpful technique in diagnosis of benign and malignant lesions of lymph node. ${ }^{3}$ In cases of highly proliferative lymphomas such as Burkitt and lymphoblastic lymphoma, FNA can provide a rapid and accurate diagnosis with minimal invasiveness that would be of critical importance. ${ }^{2}$

The role of FNAC alone remains controversial in lymphoma diagnosis and classification. ${ }^{4}$ Several ancillary techniques have been attempted to supplement cytomorphology such as Immunocytochemistry (ICC) on FNA smears or cell block sections (CB-ICC), Immunoglobulin light chain restriction (IgLCR) by Flow cytometry and Flowcytometric immunophenotyping (FCI) on FNA material. ${ }^{5}$

Cell block preparation from the same FNA material is a useful adjunct to FNA smears as it optimally utilises the aspirated material and also allows for further tests like immunocytochemistry and even molecular studies. It is useful for establishing a more definitive cytopathologic diagnosis and categorization of tumors that otherwise may not be possible on FNA smears alone.

The cell block has an advantage of short 6 or 12 hour processing schedule routinely used for small biopsy specimens. The limited exposure to alcohol, xylene, and paraffin baths minimizes the artifacts of cellular shrinkage and loss of cytologic details. For the same reasons, Nathan alcohol formalin substitute (NAFS) fixation and the short processing schedule also enhance the immunohistochemical staining, requiring no protease pre-treatment for the exposure of antigenic sites. $^{6}$

\section{Materials and Methods}

The present study performed at the Department of Pathology, Dr Ram Manohar Lohia Institute of Medical Sciences, Lucknow (U.P.) included 65 patients with lymphadenopathy and clinical \&/or cytomorphological suspicion of non-Hodgkin lymphoma enrolled with prior informed consent. FNAC was performed in all 
patients from representative lymph nodes by nonaspiration and aspiration technique using 22 to $24 \mathrm{G}$ needle. Wet fixed as well as air dried FNA smears were prepared. Extra FNA pass were performed to collect material for cell block in freshly prepared Nathan alcohol formalin substitute (NAFS) consisting of 9 parts of $100 \%$ ethanol and 1 part of $40 \%$ formaldehyde. Smears were stained with Hematoxylin and Eosin (H\&E), and May-Grunwald-Giemsa. Immunocytochemistry on cell blocks (CB-ICC) was performed using method from Bancroft $\mathbf{J}$ and Stevens (1990) with minor lab modifications. CD20, CD3, CD4, CD8, KI-67, CD23, CD5, CD10, Cyclin-D1, TDT (DAKO Denmark) antibodies were used.

\section{Results and Discussion}

The patients ranged from 15 years to 78 years of age. There were $44(67.8 \%)$ male and $21(32.3 \%)$ female patients. Cervical lymph nodes were the most common site followed by generalized lymphadenopathy. 63 cases were being investigated for primary diagnosis and 2 cases were recurrent NHL. The cases were categorised on FNAC as lymphoproliferative disorder (LPD) suggestive of NHL (47), LPD suggestive of HL (6), malignant round cell tumor (6) and inconclusive (6). Out of 65 cases, subsequent histopathology was available in 41 cases. The FNA material collected for cell block showed adequate sample yield in 53 out 65 $(81.5 \%)$ cases. Using CB-ICC these 53 cases were categorised as High grade B - cell NHL (28 cases), Low grade B - cell NHL (8 cases), T-NHL (3 cases), Inconclusive (7 cases) and others (Non hematolymphoid) (7 cases). Out of 53 cell blocks, subsequent biopsy was received in 30 cases. These cases were categorized on cell block and confirmed by HPE as DLBCL (13cases), DLBCL with Burkitt-like features (1 case), SLL (2 cases), SLL with large cell transformation ( 2 cases), MCL (1 case), PTCL ( 2 cases), ALCL (1 case). Amongst the Non hemato-lymphoid 'Others' which did not reveal NHL on cell block, subsequent biopsy confirmed diagnosis as Rhabdomyosarcoma (1 case), poorly differentiated carcinoma (1case) and metastatic carcinoma (1case). One case which was categorised as NHL, but not further classified on CB-ICC, was finally diagnosed on biopsy with IHC as T-cell histiocyte rich large B-cell lymphoma. Another case which was categorised as NHL on CB-ICC, was diagnosed on biopsy as reactive lymphadenitis. 4 cases which were inconclusive on $\mathrm{CB}$ ICC were diagnosed on subsequent biopsy as DLBCL (3cases) and MCL (1 case). Thus, considering biopsy with IHC as gold standard method for diagnosis, the sensitivity, specificity, positive predictive value and negative predictive value of CB-ICC in diagnosis of NHL were $84.6 \%, 75 \%, 95.6 \%$, and $42.8 \%$, respectively.
There are several methods for cell block preparation described in literature which use a wide range of fixatives, primarily buffered formalin, neutral buffered formaldehyde solution, Bouin solution, picric acid, Carnoy fixative, and ethanol. ${ }^{6-10}$ Formalin, an acceptable tissue fixative, has been used widely for cell blocks by researchers. In our experience, formalin combined with ethanol makes a satisfactory fixative for preservation and discrimination of nuclear and cytologic details. In our lab we found that the method described by Nathan et al $(2000)^{6}$ was best suited, in terms of ease of preparation, quality of fixation, cytomorphology and subsequent ICC application. This method was therefore used in the present study with minor modifications.

Out of 53 cases in which cell block was prepared, $28(52.8 \%)$ were HGB-NHL, 08(15.1\%) were LGBNHL, $03(5.6 \%)$ T-NHL, $07(13.2 \%)$ were non lymphoma cases and 06(11.3\%) inconclusive cases (Table 1). Subsequent biopsy was received in 30 $(56.6 \%)$ cases (Table 2) and reported as B NHL 24(80\%) [(DLBCL(13), Diffuse large B-cell type with Burkitt-like features(1), SLL(2), SLL with large cell transformation(2), MCL(1); T-NHL 03(10\%) [PTCL(2), ALCL(1)] and 03 cases which were tumors other than NHL [RMS (1), Poorly differentiated carcinoma (1) and Metastatic adenocarcinoma (1). One case which was NHL on CB-ICC but could not further classified was finally diagnosed on biopsy with IHC as $\mathrm{T}$-cell/histiocyte rich large B-cell lymphoma. This is a true limitation of CB-ICC because diagnosis of TCHRLBCL requires more detailed IHC workup and a pattern identification which is feasible only on excisional biopsy. Another case which was false positive for NHL on cell block ICC was diagnosed on biopsy as reactive lymphadenitis. Two cases were false negative on cell block ICC, were diagnosed on biopsy as PTCL $(n=2)$. Considering histology as the gold standard for diagnosis, the sensitivity, specificity, PPV and NPV of CBICC in diagnosis of NHL were $84.6 \%$, $75 \%, 95.6 \%$, and $42.8 \%$, respectively in our study. In a similar study of Zhang S et al. ${ }^{4}$ who studied 177 cases and 97 cases of lymphoma definitively diagnosed by cell block analysis, including 9 classical Hodgkin lymphoma (CHL) cases and 88 NHL cases. Using surgical biopsy results as controls, their accuracy of lymphoma sub-classification by cell block analysis was $87.5 \%(77 / 88)$ for NHL. They obtained very high sensitivity (99.0\%), specificity $(95.96 \%)$, PPV (97.1\%), and NPV $(98.6 \%)$ for the discrimination between lymphoma and benign reactive hyperplasia. In an another study by Tuhin Paul et al who compared the relative usefulness of FCI and $\mathrm{CB}-\mathrm{ICC}$ in reaching a diagnosis of NHL found that the two techniques were largely complementary to each other in a good number of cases. They showed that out of 61 cases, 45 (74\%) were diagnosed by flowcytometric immunophenotyping (FCI) as compared to $41(67 \%)$ by CB-ICC with a high 
concordance. ${ }^{11}$ Robins et al ${ }^{12}$ have also evaluated the relative efficacy of FCI and ICC on cytospin preparation and reported a diagnostic concordance of $97 \%$ between FCI and cytospin ICC. They found that CB-ICC is especially useful if a nonlymphomatous malignancy is being considered in the differential diagnosis. $^{13}$

The diagnosis of NHL through FNA cytomorphology alone has limitations. Adjunct method like immunocytochemistry on cell block can be helpful in the diagnosis and categorisation of Non-Hodgkin Lymphoma. However there are only few studies from India to substantiate these findings. Our findings from this study are comparable to those in the published literature.

We found that there are technical limitations with ancillary methods which lead to low negative predictive value for these tests. Therefore, in our opinion, although the adjunct methods have good sensitivity and high specificity but histopathology examination of tissue biopsy with IHC still remains the gold standard. However morphological correlation with FNA smears and limited IHC panel can provide valuable results in terms of low grade versus high grade lymphoma as well as to differentiate between $\mathrm{B}$ and $\mathrm{T}$ cell lymphoma which could be very helpful in clinical management of NHL cases where subsequent biopsy is not available. Our results implicate that cell block ICC is a reliable and useful adjunct to FNAC for the diagnosis and broad categorisation of lymphoma. Tissue biopsy for confirmation of diagnosis may even be deferred, especially in high tumor burden cases, where crucial time to start therapy may be lifesaving.

Table 1: Distribution of cases taken for ICC on cell block

\begin{tabular}{|c|c|c|c|c|c|c|c|}
\hline \multirow[t]{2}{*}{ FNA Categories } & \multirow[t]{2}{*}{ Number } & \multicolumn{6}{|c|}{ ICC ${ }^{*}$ on cell block } \\
\hline & & $\begin{array}{c}\text { No. of cases } \\
\text { with adequate } \\
\text { cell block } \\
\end{array}$ & $\begin{array}{l}\text { LG B- } \\
\text { NHL }\end{array}$ & $\begin{array}{l}\text { HG B- } \\
\text { NHL }\end{array}$ & $\begin{array}{c}\text { T } \\
\text { NHL }\end{array}$ & $\begin{array}{l}\text { Inconclu- } \\
\text { sive }^{\#}\end{array}$ & Others \\
\hline $\begin{array}{l}\text { LPD suggestive of } \\
\text { NHL }\end{array}$ & 47 & 40 & 07 & 27 & 01 & 05 & 00 \\
\hline $\begin{array}{l}\text { LPD suggestive of } \\
\text { HL }\end{array}$ & 06 & 04 & 00 & 00 & 00 & 02 & 02 \\
\hline $\begin{array}{l}\text { Malignant round } \\
\text { cell tumor }\end{array}$ & 06 & 04 & 00 & 00 & 01 & 00 & 03 \\
\hline Inconclusive & 06 & 05 & 01 & 01 & 01 & 00 & 02 \\
\hline Total & 65 & 53 & 08 & 28 & 03 & 07 & 07 \\
\hline
\end{tabular}

Table 2: Cell block ICC and histopathology correlation

\begin{tabular}{|c|c|c|c|}
\hline $\begin{array}{c}\text { CBICC } \\
\text { categories }\end{array}$ & $\begin{array}{c}\text { Cell block } \\
\text { Prepared } \\
\text { (No. of cases) } \\
\end{array}$ & $\begin{array}{l}\text { Subsequent } \\
\text { Biopsy available } \\
\text { (No. of cases) } \\
\end{array}$ & HPE and IHC diagnosis \\
\hline HG BNHL & $28(52.8 \%)$ & 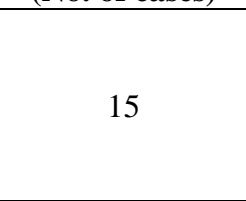 & $\begin{array}{l}\text { DLBCL }(\mathrm{N}=13) \\
\text { Diffuse large B-cell type with burkitt like features } \\
(\mathrm{n}=1) \\
\text { T cell/histiocyte rich large B cell lymphoma }(\mathrm{n}=1) \\
\text { HPE not available }(\mathrm{n}=12)\end{array}$ \\
\hline LG BNHL & $08(15.1 \%)$ & 05 & $\begin{array}{l}\text { SLL }(n=2) \\
\text { SLL with large cell transformation }(n=2) \\
\text { Marginal zone lymphoma }(n=1) \\
\text { Reactive lymphadenitis }(n=1) \\
\text { HPE not available }(n=2)\end{array}$ \\
\hline T-NHL & $03(5.6 \%)$ & 03 & $\begin{array}{l}\text { PTCL }(n=2) \\
\text { ALCL }(n=1)\end{array}$ \\
\hline Others & $07(13.2 \%)$ & 03 & $\begin{array}{l}\text { Rhabdomyosarcoma }(n=1) \\
\text { Poorly differentiated carcinoma }(n=1) \\
\text { Metastatic carcinoma }(n=1) \\
\text { HPE not available }(4)\end{array}$ \\
\hline Inconclusive & $06(11.3 \%)$ & 04 & $\begin{array}{l}\operatorname{DLBCL}(n=3) \\
\operatorname{MCL}(n=1)\end{array}$ \\
\hline Total & 53 & 30 & \\
\hline
\end{tabular}




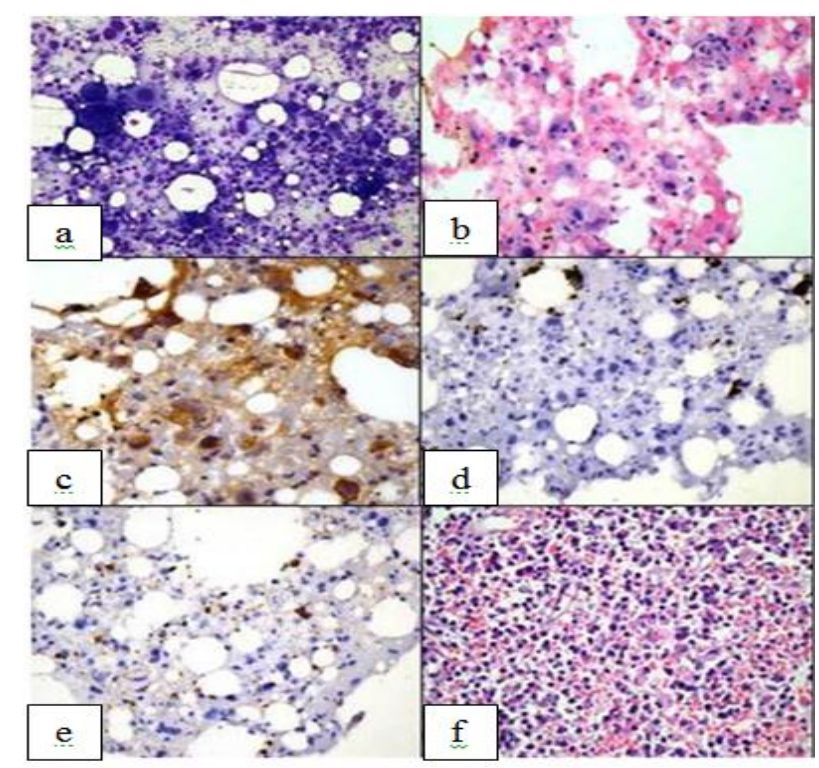

Fig. 1: (a-f) Anaplastic large cell lymphoma

a: FNA smear- shows large mononuclear \& multinucleated atypical lymphoid cells small lymphocytes (MGG 200X); b. Cell Block- shows pleomorphic large cells admixed with few smaller lymphoid cells (H\&E 200X); c: Cell Block: shows membrane and cytoplasmic positivity for CD30 in the large cells (ICC 400X); d: Cell Block: shows no staining for ALK1 in the large cells (ICC 400X); e: Cell Block: shows no staining for CD20 in the large cells, occasional scattered small lymphocytes are positive (ICC 200X); f: Biopsy- shows similar pleomorphic large cells admixed with smaller lymphoid cells (H\&E 200X)

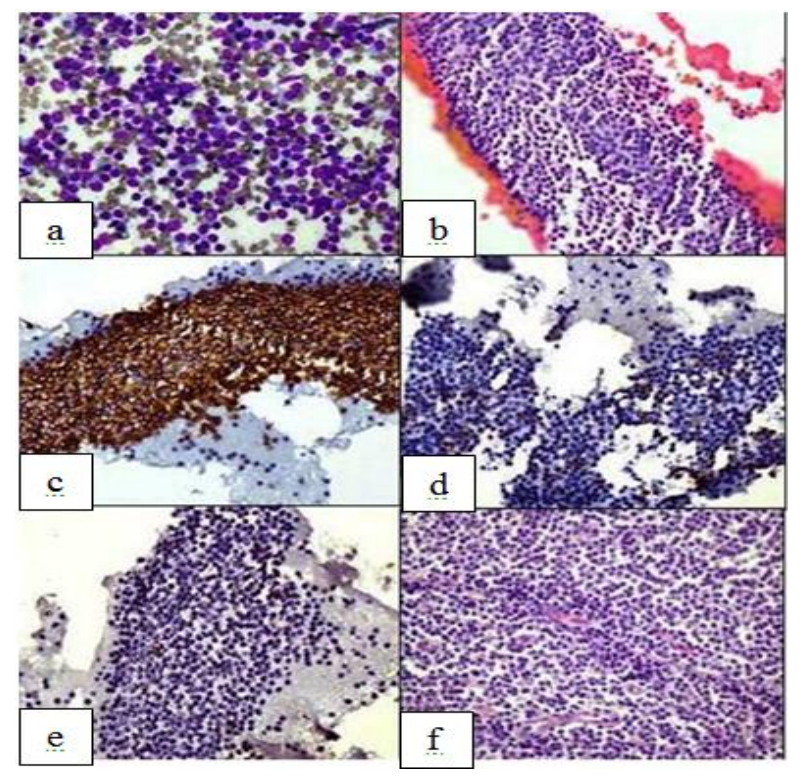

Fig. 2: (a-f) Small lymphocytic lymphoma

a: FNA smear- Shows uniform small to medium sized cells with clumped chromatin \& few large cells (MGG 200X); b: Cell Block- Shows sheets of small to medium sized cells with few scattered large cells (H\&E 200X); c: Cell Block: shows diffuse membrane positivity for CD20 in the cells(ICC 200X); d: Cell Block: shows few scattered small lymphocytes positive for CD3 (ICC 200X), e: Cell Block: shows nuclear staining for Ki67 in very few cells (ICC 200X); f: Biopsy - Shows sheets of small to medium sized cells with clumped chromatin (H\&E200)

Financial support and sponsorship: Nil

Conflicts of Interest: There are no conflicts of interest

\section{References}

1. Swerdlow S, Steven H, Campo E, Harris N, et al, "WHO Classification of Tumors of Haematopoietic And 
Lymphoid Tissue" Lyon, France: Intenational Agency for Research on Cancer Press (2008).

2. Young NA, Al-Saleem TI, Ehya H, Smith MR, "Utilization of fine needle aspiration cytology and flow cytometry in the diagnosis and subclassification of primary and recurrent lymphoma" (1998) 84(4):252-61.

3. Ensani F, Mehravaran S, Irvanlou G, Aghaipoor M et al, "Fine-needle aspiration cytology and flow cytometric immunophenotyping in diagnosis and classification of non-Hodgkin lymphoma in comparison to histopathology" Diagn Cytopathol (2012) 40(4):305-10.

4. Zhang S, Xiaomeng Yu, Zheng Y, Yang Y et al, "Value of fine needle aspiration cell blocks in the diagnosis and classification of lymphoma” Int J Clin Exp Pathol (2014) 7(11):7717-7725.

5. Meda BA, Buss DH, Woodruff RD, Cappellari JO, "The Usefulness and Limitations of Combined Fine-Needle Aspiration Cytomorphology and Flow Cytometry" Am J ClinPathol (2000) 113:688-699

6. Nathan NA, Narayan E, Smith MM and Horn MJ, "Improved Preparation and Its Efficacy in Diagnostic Cytology" Am J Clin Pathol (2000) 114:599-606.

7. Domagala WM, Markiewski M, Tuziac T, Kram A, Weber K, Osborn M, "Immunocytochemistry on fine needle aspirates in paraffin mini blocks" Acta Cytol. (1990) 34:291-6.

8. Bales CE, Durfee GR, “Cytological technique, part 1. In: Koss LG, ed. Diagnostic Cytology and Its

Histopathologic Bases" 4th ed. Philadelphia, PA: Lippincott (1992) 1451-1474.

9. Gurley AM, Silverman JF, Lassaletta MM et al, "The utility of ancillary studies in paediatric FNA cytology" Diagn Cytopathol. (1992) 8:137-146.

10. Zito FA, Gadaleta CD, Salvatore C, et al, "A modified cell block technique for fine needle aspiration cytology" Acta Cytol. (1995) 39:93-99.

11. Paul T, Gautam U, Rajwanshi A, Das A, Trehan A, Malhotra P, et al, "Flow cytometric immunophenotyping and cell block immunocytochemistry in the diagnosis of primary Non-Hodgkin's Lymphoma by fine-needle aspiration" Experience from a tertiary care center. J Cytol (2014) 31:123-30.

12. Robins DB, Katz RL, Swan F Jr, Atkinson EN, Ordonez NG, Huh YO, "Immunotyping of lymphoma by fineneedle aspiration. A comparative study of cytospin preparations and flow cytometry" Am J Clin Pathol (1994) 101:569-76.

13. Mayall F, Dray M, Stanley D, Harrison B, Allen R, "Immunoflowcytometry and cell block immunohistochemistry in the FNA diagnosis of lymphoma" A review of 73 consecutive cases" J Clin Pathol (2000) 53:451-7. 